\title{
( Patterns of Party Evaluations
}

\author{
Kees Aarts and Bernt Aardal
}

\subsection{Introduction}

in THEIR COMPETITION FOR VOTES, POLITICAL PARTIES ARE CONFRONTED with two contradictory forces. On the one hand, signaling moderation and centrism in their ideological position usually helps in securing votes from the moderate and centrist voters, who typically form a large part of the electorate. On the other hand, signaling commitment to a clear ideological stance enhances the party's credibility and helps building up a strong party image (Hinich and Munger 1994).

How to deal with the tension between moderation and commitment is one of the recurring questions for political parties all over the world. Should they take moderate, centrist ideological standpoints, or should they take positions that are as clear and unambiguous as possible? From an electoral viewpoint, the latter strategy will only work when voters understand and reward those parties which choose sides. Do voters reward parties that take a clear side on the issues, or are voters on the whole more inclined to prefer the party that is merely close to their own position? And how does the political-institutional environment affect the chances of success of this strategy? These questions have been at the core of the debate on proximity versus directional models of party evaluation, which started with Rabinowitz and Macdonald's (1989) seminal APSR article. Since then, research on these questions has been mostly limited to single-country studies (e.g. Macdonald et al. 199I), or internationally comparative studies of a limited set of countries (e.g. Iversen 1994). In this contribution, we cover as many as 66 democratic elections from all over the world in an attempt to obtain results that are as general as possible. We will use data from Modules I and 2 of the Comparative Study of Electoral Systems (csEs), which has been conducted in many countries on different continents starting in 1996. Jacques Thomassen was involved from the very start with the cses project, as co-author of its original stimulus paper of 1994 and as chair of its first Steering 
Committee. His contributions, as all are aware who have seen cses develop, were extremely important for the success of this worldwide endeavor.

However, a price is to be paid for worldwide coverage: the tertium comparationis - the aspects on which different elections are compared, must be so general and abstract that election-specific issues and circumstances cannot play a great role in the analysis. The tertium comparationis in this chapter is formed by the positions of parties and survey respondents on the left-right scale, which is often regarded as an abstract summary of the main ideology in party systems. But left-right ideology is not equally important in the political discourses of very different party systems. A secondary question of our analysis will therefore be, to which extent left-right ideology can be used as a shortcut or ideological positions in different polities.

Evaluating the dilemma of party strategy with empirical data on voters and parties is not only relevant from a theoretical perspective, but it may also have consequences for the way electoral behavior is modeled. For over 50 years, views on how voters make up their mind when deciding which party or candidate to vote for have been molded by the proximity model of political choice. The proximity model can be regarded as a decision-theoretic translation of one side of the tension referred to above, namely the tendency towards moderation. It is based on a few fundamental assumptions (Black 1958). Most importantly, the preference order of the voters for the competing parties is determined by the closeness or proximity of these parties to the voter's ideal point on the most important dimension(s) of politics. In other words, the preference curves of voters for the parties are assumed to be singlepeaked. Suppose further that in a polity, parties and voters can be positioned on a single dominant, ideological dimension. Support for a political party would then be highest among those voters who occupy the same position on the ideological dimension as that party - for voters on either side of the party position, support drops off the further away voters locate themselves. The proximity approach has led to the formulation of the median voter theorem (Downs 1957; Black 1958), which states that in the case of two-party competition on a single dimension, the voter on the median position decides which party will win the election. A vast literature exists which looks at the generalizability of this rather specific result (for an overview see, for example, Mueller 1989).

Since the early I960s, the proximity model has also been criticized because of its lack of empirical support (e.g. Stokes I963). Since the end of the I98os, the proximity approach has been directly challenged by an alternative theory of party support - directional theory (Rabinowitz and Macdonald r989; Macdonald et al. r99I). Directional theory assumes that the ideological dimension is split in two directions, starting from a neutral midpoint. As in proximity theory, parties and voters occupy positions along this dimension. But in contrast to proximity theory, party support is not determined by the closeness of voter and party, but by direction and intensity instead. Direction refers to whether parties and voters are on one or the other side of the center position. Intensity refers to the exact position of party and voter, either on the left-hand or on the right-hand side of this center. The basic question for 
voters in directional theory is not: "Which party is closest to my own ideological position?", but rather: "Which party most forcefully voices my ideological leaning while remaining trustworthy?"

The introduction of an alternative, directional explanation of issue- and ideology-based party support has given rise to a lively debate on models and methods (key publications include, apart from those already mentioned: Westholm (1997); Macdonald et al. (1998); Westholm (200I); Macdonald et al. (200I); the debate has been placed into a wider theoretical perspective by Merrill and Grofman (I999)). We are not addressing that debate here. In our view, discussion about which of the two main models is correct, in the sense of corresponding to reality, rests upon the mistaken assumption that the models are mutually exclusive. Starting with Rabinowitz and Macdonald's (I989) 'mixed model', empirical analyses of issue- and ideology-based voting have incorporated both proximity and directional elements. The empirical analyses show how important these two elements are for the evaluation of political parties.

In this contribution we primarily address the tenability of the single most basic assumption underlying the proximity model. This is the assumption that support for a party peaks among those voters who occupy ideological positions near the position of the party - and drops off along both sides of the party position. Listhaug et al. (1994) provided an analysis of this assumption for six northern European democracies, and found evidence in favor of the directional model (with some noteworthy exceptions). In this contribution we follow their analytical strategy, but the analysis is expanded to 66 elections in 37 different democracies on five continents, using Modules I and 2 of the Comparative Study of Electoral Systems.

The chapter proceeds as follows. First, the two competing models of party support are presented, and some testable hypotheses are developed. Second, the data and research strategy are introduced. Thirdly, the results from the empirical analysis are presented - initially for a single election in some detail, and thereafter for all other elections investigated. Fourthly, the results of the empirical analysis are used as materials for a higher-order analysis in which the estimated coefficients are used as data. The chapter concludes with a summary of findings and some implications.

\subsection{Models of party support}

\subsubsection{Ideology and the left-right scale}

Support for political parties depends on many factors. Personal characteristics of the voter, including demographic characteristics, help explain why he or she likes one party better than another. Party characteristics, including its size, age and leadership, contribute another part of the puzzle. From the viewpoint of political theory, however, the most interesting variables explaining party support are those which 
refer to the political convictions of the voters and the parties: positions on political issues, government policies, and more generally ideological positions.

Ideology, according to Downs' $(1957,96)$ definition, is a verbal image of the good society and of the chief means for constructing such a society. Uncertainties in the world of politics make it difficult for voters to rationally compare the positions of political parties on specific issues. Ideologies can serve as decision-making shortcuts for these voters: both parties and voters can use the language of ideology to communicate their political positions to each other without getting trapped in the details.

Ideologies may be one-dimensional or multi-dimensional. The more abstract the formulation and the labels used are, the less need there will be for more than a single dimension. One of the most abstract, and perhaps as a consequence most-often used shortcuts is the position of voters and parties on the left-right scale. In many democracies, both voters and parties use the labels 'left' and 'right' (and varieties such as 'far left' or 'extreme right') to denote their basic political outlook. In spatial terminology, both the parties and the voters occupy relatively stable positions on the left-right continuum.

The left-right scale as a measure of ideological self-placement has been criticized for various reasons. One of the most important criticisms holds that left-right selfplacement is a shortcut of partisan identification rather than issue positions (Inglehart and Klingemann 1976); a related criticism states that ideological positions are simply too complicated to be understood by a large part of the electorate (Converse 1964; see also Fuchs and Klingemann 1989). Self-positions on the left-right scale thus reflect a combination of elements of party identification and substantive, issue-related ideological elements. Analyzing eight West European democracies, Huber (1989) found that the partisan component does not generally dominate the issues component of these scales. More recently, studies have shown the substantive loading of the left-right scale in a variety of new democracies, including Russia (Evans and Whitefield I998), South Korea (Shin and Jhee 2005) and other countries (Mainwaring and Torcal 2006). In this contribution, we start with the assumption that the left-right dimension does have a substantive meaning in all the elections analyzed - even though this substantive meaning may be limited to parts of the electorate with a higher education. For those who do not primarily assign a substantive meaning to left and right, the concepts are still useful as a summary of the positions of political parties and of the voter him- or herself.

\subsubsection{Ideology-based party evaluation}

We now briefly outline the different models of ideology-based party evaluation. More extensive descriptions can be found in, for example, Davis et al. (1970) and Rabinowitz and Macdonald (1989). It is assumed that party and voter locations on the ideological continuum - the left-right scale - are given, according to the proximity model of party support, affect of a voter $i$ for a party $j$ simply is a (negative) 
function of the distance between the voter's position $\left(L_{i}\right)$ and that of the party $\left(L_{j}\right)$ (e.g. Listhaug et al. I994: II4):

(I) $\quad \mathrm{A}_{\mathrm{ij}}=-\left(\mathrm{L}_{\mathrm{i}}-\mathrm{L}_{\mathrm{j}}\right)^{2}$

In this formula, distance is expressed as the square of Euclidean distance. The fundamental prediction of the proximity model is that voters like best the party that is ideologically closest to their own ideological position, and that their support for parties drops off the further the parties are removed from the voter's position. For a single voter whose ideological position is on the left $(-2)$, and three parties located at the right, center and left respectively, the proximity model is graphically illustrated in Figure 9.r. The single-peaked evaluation curve of the voter is at its maximum

Figure 9.1 Party evaluation under the proximity model (simulated data)

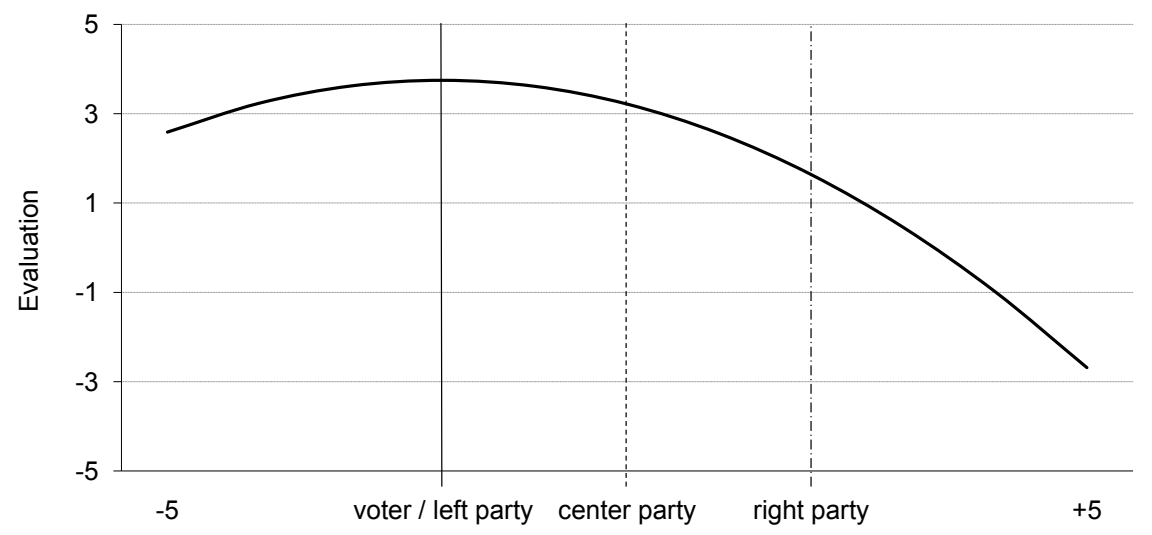

Left-Right position

at position -2 , where both the voter and the left party are located. At both sides of this maximum, evaluation drops off.

The directional model developed by Rabinowitz and Macdonald (1989) is based on a similar spatial representation of party and voter locations as the proximity model. An important difference is that the directional ideological continuum has a neutral midpoint and two distinct directions on either side of this midpoint. Moving left from this midpoint, ideological positions are left with an increasing intensity. Moving right, ideological positions are increasingly right.

The key assumption of the directional model is that voters are more attracted to parties that intensively voice their own ideological position (left or right) than to 
parties that are closer to the neutral point. Such parties are seen as committed. That is, up to a certain limit: when a party's position is really extreme on the ideological continuum, it will lose support. For all 'normal' parties, however, voters' affect will vary with the intensity with which both the voter and the party choose their sides. This assumption is modeled as follows:

(2) $\quad \mathrm{A}_{\mathrm{ij}}=\mathrm{L}_{\mathrm{i}}^{*} \mathrm{~L}_{\mathrm{j}}-\mathrm{P}_{\mathrm{ij}}$

Voter is affect for party $\mathrm{j}$ is directly related to the product of the position of the voter and that of the party on the ideological continuum. A penalty $P_{i j}$ for the party is subtracted when the party is too extreme. Normally, when parties do not take irresponsible stances, $P_{i j}$ will be zero and the last term in the model can be ignored, ${ }^{1}$ so that the model simplifies to:

(2a) $\mathrm{A}_{\mathrm{ij}}=\mathrm{L}_{\mathrm{i}}^{*} \mathrm{~L}_{\mathrm{j}}$

When the voter and the party are on opposite sides of the neutral point, affect will be increasingly negative when the party and/or the voter are more intense. Rather than single-peaked preference curves, the directional model assumes monotonically increasing or decreasing preference curves. The more intense the party position (up to the limit of responsibility), the steeper the voter's preference curve. In this model, parties positioned near or at the neutral midpoint of the ideological continuum will provide the weakest cues to voters, and will therefore produce relatively flat

Figure 9.2 Party evaluation under the directional model (simulated data)

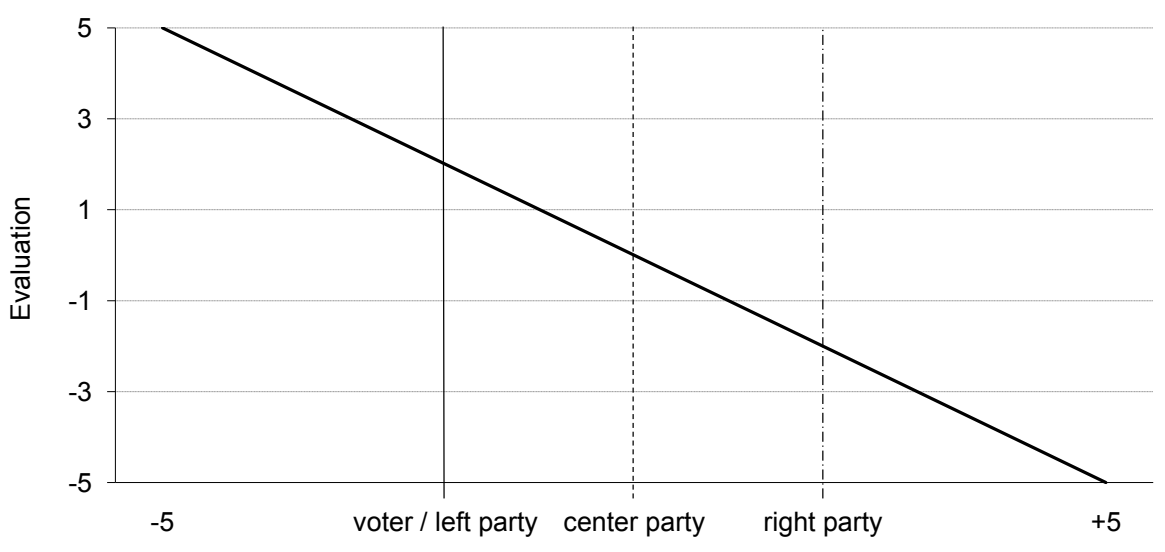


preference curves. For the same situation as in Figure 9.I, evaluation according to the directional model is illustrated by Figure 9.2. In contrast with Figure 9.I, the voter's evaluation of the party does not drop off at the left of his own ideological position. Rather, it increases further, indicating that parties to the left of the voter's position would be evaluated even higher than the left party included in Figure 9.2. ${ }^{2}$ When a party would be too extreme, however, it would become less attractive. We assume that this situation does not occur on the part of the left-right continuum shown here.

\subsubsection{From individual evaluations to support curves}

We now turn to the implications for the electorate as a whole. Which predictions can be derived for the pattern of party evaluations under the proximity model and under the directional model when not just one, but millions of voters are considered? ${ }^{3}$

Under either the proximity or the directional model, individual evaluation curves such as those in Figures 9.I and 9.2 can be constructed for every voter. The ideological positions of the voters vary. Depending on the voter's ideological position, the maximum of the curve under the proximity model, or the slope and sign of the curve under the directional model, will be different. Distinct individual evaluation curves can be drawn for voters at each position on the ideological continuum.

Moreover, different voters at the same position on the ideological continuum may have different interpretations and uses of the evaluation scale - for example, some tend to evaluate all parties rather highly whereas others are more reserved in this respect. Such individual differences are typically non-systematic, and can therefore be ignored with sufficiently large numbers of voters at each ideological position. As a result, a single evaluation curve provides a valid summary of the individual evaluations of many voters with the same position on the ideological spectrum, and this evaluation curve can by the same logic be meaningfully compared with curves constructed for voters at other ideological positions.

Finally the viewpoint is changed from the voters to that of the political parties. Every party also occupies a position on the ideological continuum. The party position at some point cuts the evaluation curves of voters. By connecting the evaluations of each party for voters at different positions on the ideological continuum, party support curves are obtained. The proximity and the directional models predict different patterns of support curves. These different patterns, for three hypothetical political parties (left, center, and right) are shown in Figures 9.3 and 9.4 (cf. Listhaug et al. I994: II5). Despite the resemblance between Figures 9.I and 9.3, and 9.2 and 9.4, the interpretation of the figures is now completely different. Whereas Figure 9.I depicts the individual evaluation curve of a voter under the proximity model, Figure 9.3 shows the support curves of three political parties under the same proximity logic. Similar interpretations hold for Figures 9.2 and 9.4.

Depending on which of the two models is more appropriate, descriptions of voter decision-making in elections, and more generally of voters' attitudes towards political parties, will be divergent as well. To find out which model fits the empirical data 
Figure 9.3 Party support curves under the proximity model (simulated data)

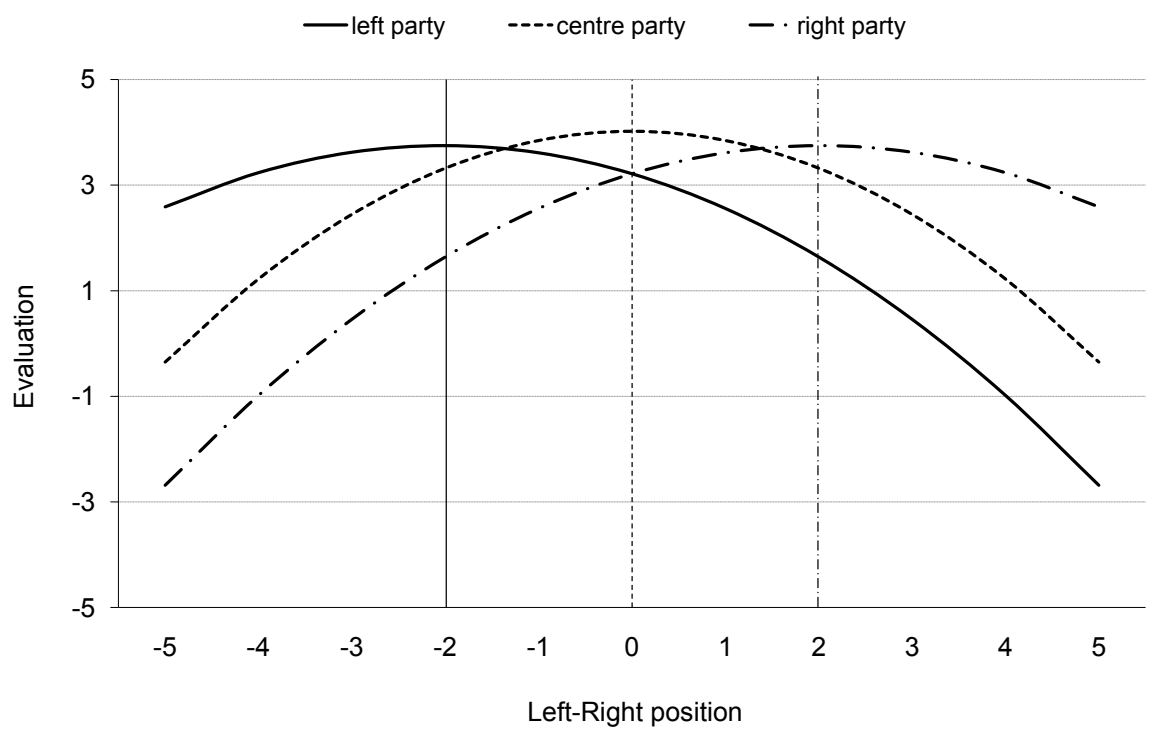

Figure 9.4 Party support curves under the directional model (simulated data)

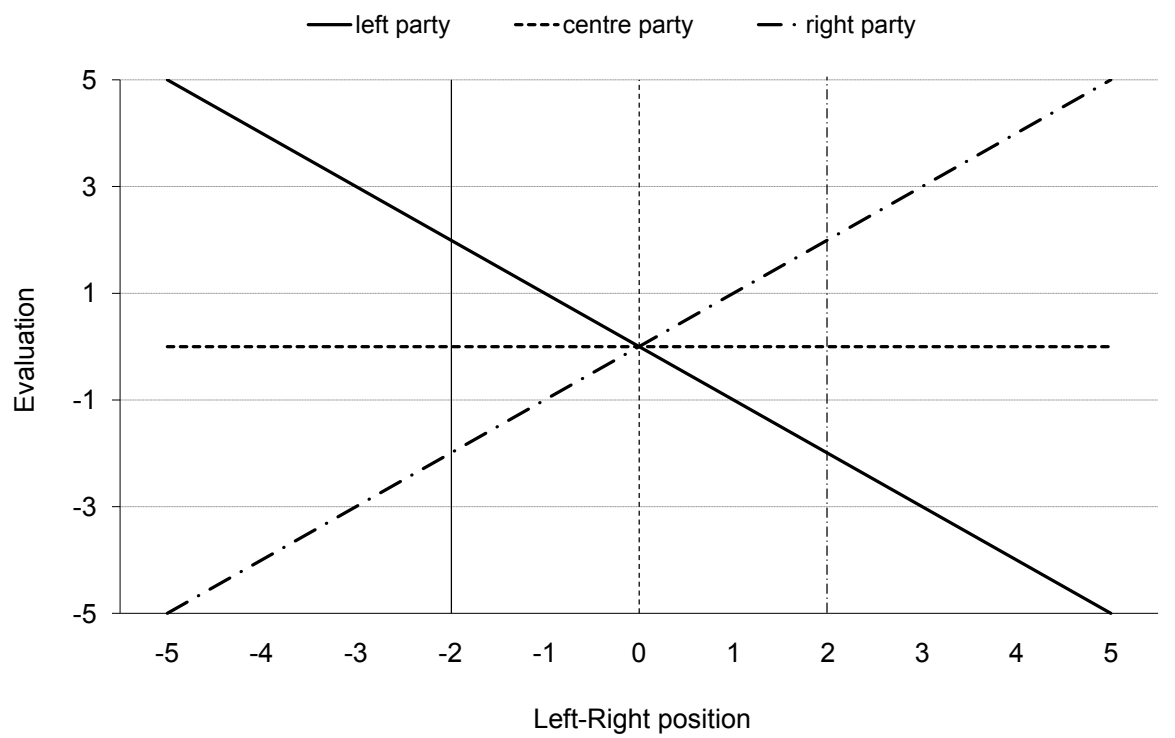


best, party support curves will be used as the tools for our subsequent analysis of the pattern of party evaluations in the real world. Before presenting the analyses, the data and the method of analysis to be used are outlined, and specific hypotheses are formulated.

\subsection{Data}

For an empirical assessment of party support curves, two pieces of information about the voters are needed: their positions on the ideological continuum, and their evaluation of the political party. Both pieces of information are routinely included in many election studies all over the world, and have been standardized in the Comparative Study of Electoral Systems (cses) which will be used in this chapter.

In this contribution we use Module I (I996-200I) and Module 2 (200I-2006, $4^{\text {th }}$ advance release) of the cses. Together, these modules contain $7 \mathrm{I}$ election studies. For various reasons, ${ }^{4}$ the total number of elections analyzed here is less, namely 66 elections (4r in Europe, 8 in Asia, 7 in Latin America, 4 in North America, 4 in Australia and New Zealand, and 2 in the Middle East). Party evaluation was assessed by asking respondents to rate the party on a scale from $\circ$ to Io, where $\circ$ means that the respondent strongly dislikes the party, and ro means that the respondent strongly likes the party. The ideological position of voters was measured by asking the respondents to place themselves on a scale running from $\circ$ to ro, where $o$ means 'left' and to means 'right.'The left-right dimension is not equally common in the ideological parlance of all political systems - therefore, in our analyses we will explicitly assess the explanatory power of left-right positions. Party evaluation and left-right placements were rescaled to the -5 to +5 interval (see below).

Extra information that will be used for interpreting the results is provided by the mean left-right ratings of the political parties by the respondents. These mean ratings of parties can be regarded as an approximation of the ideological position of the parties, and form the background against which the findings will be interpreted.

\subsection{Method of analysis}

The method of analysis to be used is parabolic regression analysis. This method provides a direct test of the proximity and directional models of party support. ${ }^{5}$ The logic is simple. In parabolic regression, party evaluation is regressed on both the voter's ideological position and on the squared ideological position. The equation thus includes both a linear and a quadratic term for ideology. When the ideology scale is centered around zero (meaning that ' 5 ' is subtracted from the original scale value measured in the survey), the linear and the squared term will hardly be correlated, so that collinearity problems are avoided. ${ }^{6}$ The parabolic regression equation to be estimated for a party is: 
(3) Evaluation $=b_{0}+b_{r}($ Ideology $)+b_{2}(\text { Ideology })^{2}+$ error

This equation can estimate both (proximity model) curves that show a peak around the party's position, and (directional model) curves that increase or decrease monotonically across the ideological spectrum. To see how the equation is related to the proximity and directional models discussed earlier, consider the following.

The ideological positions of political parties are given - in the analysis of voter support for parties, these party positions are therefore constants. The proximity model given by (I) was:

$$
\text { (I repeated) } \quad \mathrm{A}_{\mathrm{ij}}=-\left(\mathrm{L}_{\mathrm{i}}-\mathrm{L}_{\mathrm{j}}\right)^{2}
$$

This can be rewritten as:

(4) $\quad \mathrm{A}_{\mathrm{ij}}=-\mathrm{L}_{\mathrm{i}}^{2}-\mathrm{L}_{\mathrm{j}}^{2}+2 \mathrm{~L}_{\mathrm{i}}^{*} \mathrm{~L}_{\mathrm{j}}$

In $(4), L_{j}$ stands for the party position, which is fixed. Using $C$ (for 'constant') instead of $L_{\vec{j}}$, the equation can be written as:

$$
\text { (5) } \quad \mathrm{A}_{\mathrm{ij}}=-\mathrm{L}_{\mathrm{i}}^{2}-\mathrm{C}^{2}+{ }_{2} \mathrm{C}^{*} \mathrm{~L}_{\mathrm{i}}
$$

In (5), the only non-constant terms are $-L_{i}^{2}-$ a quadratic term with a negative sign - and ${ }_{2} C^{*} L_{i}$ - a linear term with the sign of $C$.

According to the directional model (in its simplified form, i.e. without the penalty term), affect is the product of the voter position and the party position on ideology:

$$
\text { (2a repeated) } A_{i j}=L_{i}^{*} L_{j}
$$

Since, again, the party position is fixed, replacing it by the constant $C$ yields:

$$
\text { (6) } \mathrm{A}_{\mathrm{ij}}=\mathrm{C}^{*} \mathrm{~L}_{\mathrm{i}}
$$

Comparing (5) and (6), it appears that when the constant terms are disregarded, the difference between the proximity and the directional model is the presence of the quadratic term $-L_{i}^{2}$ in the equation (5). When this term is negligible, the affect function simplifies to equation (6), and the directional model would hold. In contrast, when it is non-negligible, the affect function would display curvature - a necessary condition for the proximity model to hold.

Returning to the regression equation in equation (3), the coefficients $b_{I}$ and $b_{2}$ show how the voter's ideological position is linked with the evaluation of the party. When $b_{2}$ is negligible, the directional model is supported. When $b_{2}$ is negative and non-negligible, the support curve will show curvature with a maximum. The maxi- 
mum occurs where the first derivative to ideology of equation (3) equals zero; this is at the ideological position $-\left(b_{I} / 2 b_{2}\right)$. Under the proximity model, the maximum should coincide with the ideological position of the party, and it should certainly lie within the range of values of the ideology scale (i.e. in the range between -5 and +5 ). When a support curve reaches its maximum value outside the range of ideology scale values, this means that it monotonically increases (or decreases) across the full range of ideology, which would support the directional model. Finally, when $b_{2}$ is positive, the support curve has no maximum.

\subsection{Alternative predictions}

In the foregoing, a number of different predictions have been made which distinguish between patterns of support curves under the proximity model and under the directional model. The first of these is:

(I) Under the proximity model, the quadratic term in the estimated support curve is non-negligible and negative. Under the directional model, the quadratic term is negligible and/or positive.

Secondly,

(2) Under the proximity model, a peak in the support curve is located on the ideological scale at the ideological position of the party. Under the directional model, no peaks exists or - if they exist - are located outside the range of the scale.

For the question whether the analyses make any sense at all in the specific context of an election, the importance of the ideological left-right scale must be assessed. We will look at the explained variance by the parabolic regression. When the explained variance $\left(R^{2}\right)$ is very low, obviously party support depends on other, uncharted factors, and we should not attach great value to the impact of left-right ideology. Thus,

(3)For both the proximity and the directional model to hold, ideology as measured by the left-right sale must contribute to the explanation of party support.

After the initial analyses, we take the party positions on the left-right scale into consideration. The party positions are compared with the slope, and with the maximum values of the estimated support curves.

\subsection{Example: the Australian 2004 election}

As an example, consider the Australian Lower House election of 9 October 2004. This election returned the right-wing governing coalition of Liberals and National 
party into power, after a close race with the left-wing Labor party. Prime minister John Howard's Liberal party (40.9 percent of the vote) won exactly half of the seats in parliament ( 75 seats), and its coalition partner, the agrarian National party (5.9 percent) won I2 seats. Labor ( 37.7 percent) won 60 seats, and the remaining three seats were allocated to independents. The left-liberal Democrats (I.2 percent) and the Greens (7.2 percent) did not win any seats, and neither did Pauline Hanson's One Nation (I.I percent).

In the Australian National Election Study, evaluation scores for these six parties have been collected, together with the respondent's position on the left-right scale. In addition, the left-right ratings of the six parties mentioned are available, which provide the mean position of these parties in the eyes of the voters.

Six parabolic regressions were estimated, one for each party. The key results are summarized in Table 9.I.

The Australian parties depicted in Table 9.I have been ordered from left to right - from Greens to Liberals. Three parties (Greens, Labor, and Democrats) are regarded as left-wing, and three parties are seen as right-wing (One Nation, National, Liberal). In the case of Australia, the parabolic regression coefficients for all parties are fully in accordance with directional support curves. The linear coefficients for the three left-wing parties are negative (implying decreasing curves over the ideological spectrum), and those for the three right-wing parties are positive (increasing curves). The quadratic coefficients could make any curvature in the support curves visible, as required by the proximity model. But for none of the six parties is there curvature of any significance. None of the party support curves peaks within the range of the ideological spectrum.

In the case of Australia (2004), the linear coefficients follow the pattern predicted by directional theory. The slope of the evaluation curves is steepest for the most outspoken parties, and flattest for the parties closest to the center position on ideology. The two parties closest to the center position do not provide clear ideological cues to the voters, which is reflected in the relatively low $R^{2} \mathrm{~s}$ for these parties (Democrats and One Nation). The conclusion is that support for political parties in Australia follows the directional logic: voters like parties better when they are more intensively on their side when it comes to ideology.

Table 9.1 Pattern of party evaluations in the Australian 2004 election

$\begin{array}{lrrrrrr}\text { Party } & \text { Ideological position } & \text { Linear coefficient } & \text { Quadratic coefficient } & \text { Maximum } & \text { R2 } & \text { N } \\ \text { Greens } & -1.79 & -0.60 & 0.01 & \text { no maximum } & 0.17 & 1,388 \\ \text { Labor party } & -0.69 & -0.54 & -0.01 & \text { off scale } & 0.17 & 1,413 \\ \text { Democrats } & -0.59 & -0.22 & -0.01 & \text { off scale } & 0.04 & 1,388 \\ \text { One Nation } & 0.94 & 0.29 & -0.02 & \text { off scale } & 0.05 & 1,392 \\ \text { National party } & 1.59 & 0.64 & -0.01 & \text { off scale } & 0.22 & 1,386 \\ \text { Liberal party } & 2.03 & 0.92 & -0.03 & \text { off scale } & 0.33 & 1,422\end{array}$


Figure 9.5 Party support curves in Australia, 2004

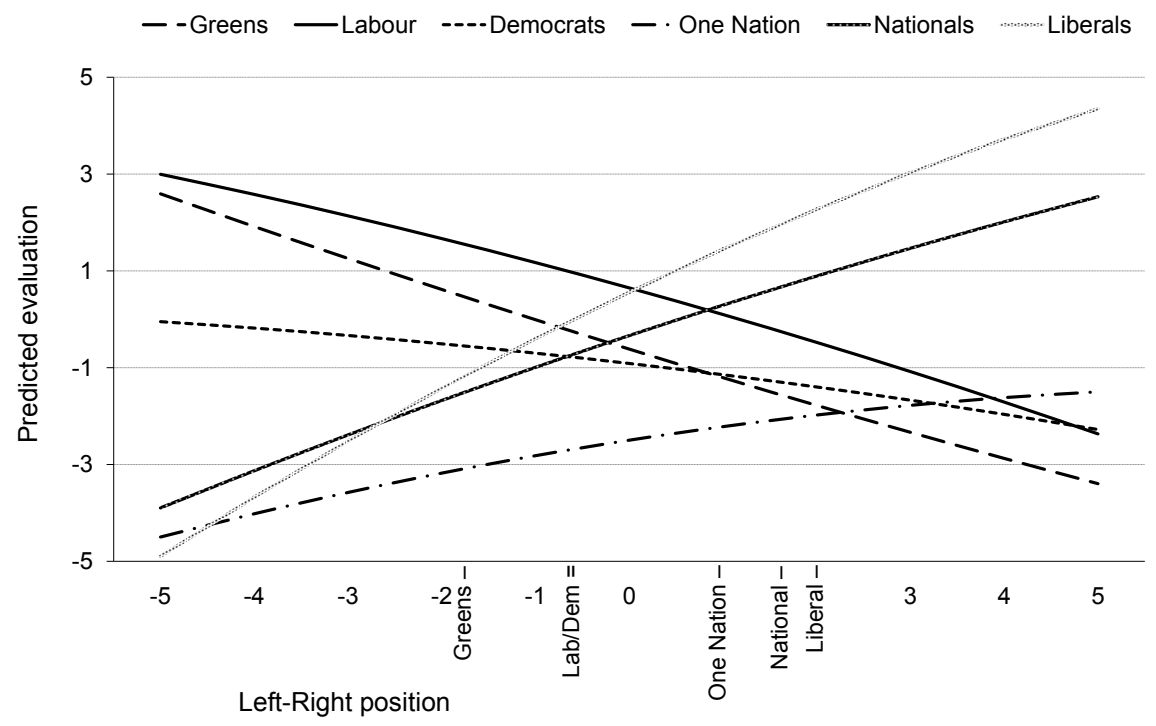

Source: Comparative Study of Electoral Systems (CSES), Module I

The results for the Australian 2004 election are graphically displayed in Figure 9.5, which depicts the estimated support curves for the six parties, and their ideological position. Compared with the information in Table 9.I, the curves in Figure 9.5 show one extra piece of information: the different intercepts of the estimated support curves $\left(b_{0}\right.$ in equation (3)). It can be seen, for example, that except from voters at the far left, the Liberal party gets generally higher evaluations than the National party; and that One Nation and the Democrats receive low evaluations practically across the board.

\subsection{Results}

In this section the main results of the analyses of all 65 elections are presented (Tables with details of the parabolic regression analyses can be obtained from the authors).

\subsubsection{Cases in which left-right ideology is unrelated to party evaluation}

We first address the requirement common to both the proximity and directional models of ideology and party support, namely that left-right ideology must con- 
tribute to the explanation of party support. When that is not the case, it does not make much sense to analyze the pattern of party support based on voters' ideological positions. In such cases, perhaps other ideological dimensions than left-right are used as the shortcut Downs (1957) referred to, or completely different factors affect the evaluation of parties.

In deciding whether left-right ideology is relevant for party support, no further reference is made to the contents of this ideology. So, when left-right ideology appears to make a difference for party evaluation, this may be either because it measures ideological thinking or because it reflects party identification.

Deciding when left-right ideology does not provide a significant contribution to the explanation of party support, is to some extent subjective. Here, two criteria are applied. The first is the absolute size of the linear and quadratic regression coefficients. In the limiting case when these are both zero, the estimated support curve is a horizontal line. When they are both close to zero, left-right ideology does not make a significant difference for the evaluation of the party. The second (and related) indicator is the explained variance of party evaluation in the parabolic regression. Table 9.2 summarizes the results of this analysis. All elections in Europe are characterized by some importance of the left-right scale for party evaluation - although some elections give rise to doubt, such as Romania (1996) and Russia (1999 and 2000). The two elections in Israel, all four in North America and all four in Australia and New Zealand also show left-right as a relevant dimension.

The left-right scale appears to be a less useful device in Latin America and in Asia. In Latin America, the elections in Mexico (1997, 2000, 2003) show a complete irrelevance of this instrument. The same holds for Brazil (2002) and Peru (2000, 20or). Only in Chile (1999) does left-right seem to make some difference. In Asia, left-right has some relevance only in the Hong Kong elections (1998, 2000, and to a lesser extent in 2004). In the Philippines (2004), Korea (2000, 2004) and Taiwan (1996, 200I) the concept appears to be meaningless from a political point of view (in the Japanese election studies, the left-right scale was excluded for this very reason).

As an illustration, the support curves estimated for the case of Taiwan (200I) are depicted in Figure 9.6. The Taiwan party system clusters on a narrow segment of the left-right dimension, with a width of I.7. The support curves for the Taiwan parties can be compared with those depicted in Figure 9.5 for the Australian case. The differences between Figures 9.5 and 9.6 are evident: whereas in Australia the support curves together practically cover the full range of the evaluation scale, in Taiwan most lines (with the exception of the 'leftist'Taiwan Solidarity Union and the 'rightist' Kwo Min Tang) are almost horizontal, and the support curves cover only the $-2-+1$ range on the evaluation scale.

Some cases that are included in the subsequent analysis have a very low proportion of explained variance in party evaluation, but at the same time some party support curves are clearly sloped. An example is provided in the two panels of Figure 9.7, which depict the support curves for the Flemish and Walloon parties in Belgium (2003). Although the $R^{2} \mathrm{~s}$ of the regressions are all rather low, the 
Table 9.2 Elections and the relevance of left-right ideology

\begin{tabular}{|c|c|c|c|}
\hline & Relevant & Not relevant & Total \\
\hline Europe & 41 & 0 & 41 \\
\hline Middle East & 2 & 0 & 2 \\
\hline Latin America & 1 & 6 & 7 \\
\hline North America & 4 & 0 & 4 \\
\hline Asia & 3 & 5 & 8 \\
\hline Australia & 4 & 0 & 4 \\
\hline
\end{tabular}

curves show slopes and for some parties curvature as well. The Walloon environmentalist party Ecolo, and the Flemish VLD and $C D \& V$ all show a peak in support near their own ideological position, suggesting that the proximity model holds for these parties. In contrast, the Walloon socialist party PS and the Flemish socialists sp.A show clear directional curves. Finally, the extreme right Vlaams Blok shows a very low evaluation across the spectrum, which steeply increases for voters at the right end.

Figure 9.6 Party support curves in Taiwan, 2001

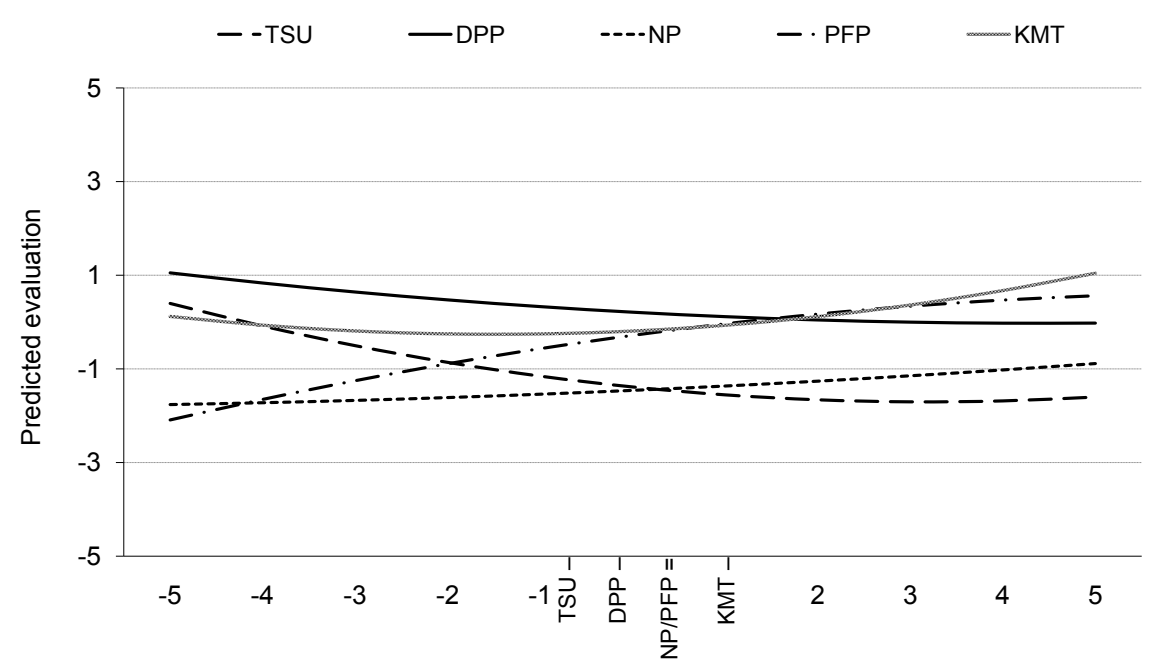

Left-Right position 
Figure 9.7 Party support curves in Belgium, 2003
a. Flanders
- -SP.A
- VLD
-..-CD\&V - NVA
$-\mathrm{VB}$

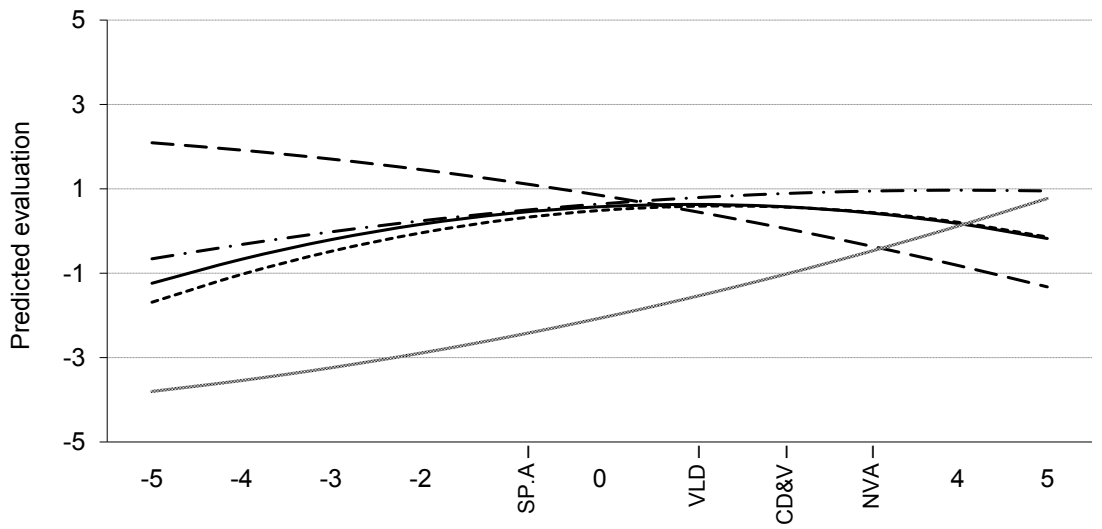

Left-Right position

b. Wallonia

- -Ecolo

-PS

$-\cdot-\cdot \mathrm{CDH}$

一 $\cdot \mathrm{MR}$

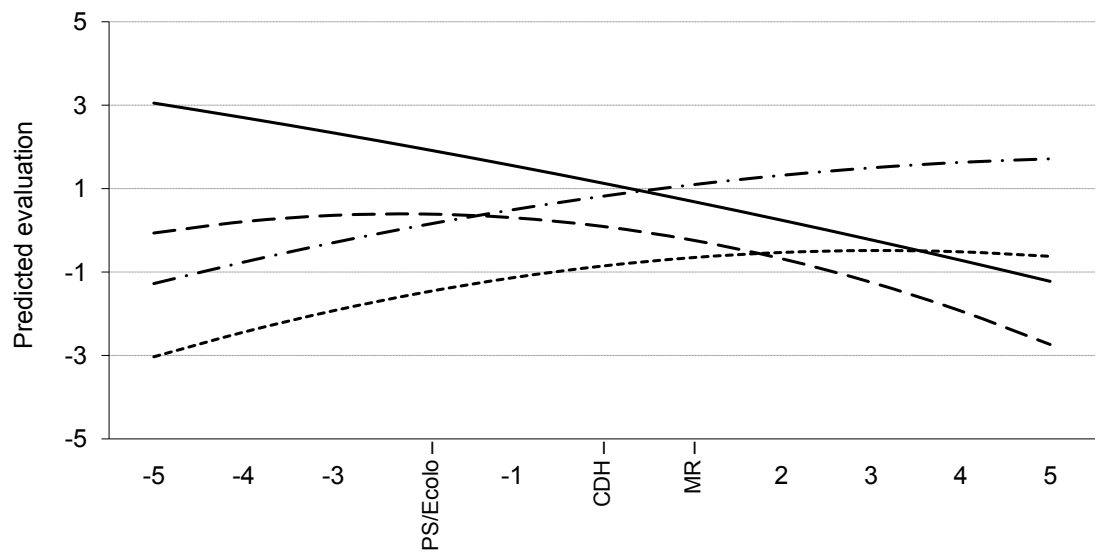

Left-Right position

Source: CSES, Module II

\subsubsection{Left-right ideology: curvature and peaks}

Table 9.3 characterizes the $3 \mathrm{I} 7$ regressions of party evaluation in terms of the type of curve that is estimated. 


$\begin{array}{lrr} & \text { n } & \% \\ \text { No maximum } & 139 & 44 \\ \text { Maximum off left-right scale } & 98 & 31 \\ \text { Maximum more than |1| off party position } & 59 & 19 \\ \text { Maximum near party position } & 21 & 7 \\ \text { Total } & 317 & 101\end{array}$

In 44 percent of the regressions, the estimated support curve has no maximum, and in another $3^{\mathrm{I}}$ percent the maximum exists but it is not within the range of the left-right ideology scale. In other words: for 75 percent of the parties investigated in this analysis, the support curve resembles the directional rather than the proximity model. This is overwhelming evidence that the proximity model does not reflect the available empirical data, supporting the contention of Rabinowitz, Macdonald and others.

In those cases in which the curve does have a maximum on the ideology scale, the estimated maximum of the curve is most often (59 of 80 cases) relatively far removed from the estimated left-right position of the party. Typically, the maximum is located at a more extreme position on the left-right scale than the party itself. Only in 7 percent of the cases is the estimated maximum near the position of the party on the left-right scale. In these 2I cases, the estimated support curve appears to conform to the proximity model.

The degree of curvature in these 2I cases varies (in some cases, such as the small Mouvement des Citoyens/Pôle Républicain (MDc/PR) of Jean-Pierre Chevènement in the French 2002 election, it is hardly noticeable). More importantly, directional- and proximity-type support curves appear to coexist. As an example, the Bulgarian party system consists of two parties located on the left (the small в s ) and the right (UDF, with I8 percent of the vote) of the ideological spectrum whose support is strongly and linearly dependent on the voters' left-right position. But it also contains a party, the National Movement Simeon II (43 percent of the vote), which is the clearest example available of a quadratic support function peaking at the party location. Typically, the NM-Simeon I is a rather centrist party on the leftright scale.

Simply counting results for different parties, directional-type support curves clearly outnumber the curves with a maximum on the scale by 3 to I (and including those cases in which the peak is located far from the party position, or in which the curvature is very low). However, the conclusion must be that there is not just one correct model of party support. Party systems shows mixtures, straight lines are not always that straight, and curved lines are not always that curved. 


\subsubsection{Slope, curvature, and party position}

We have established that the shape of party support curves, based on left-right ideology, should be regarded as variable. The shape of support curves varies within and across party systems. An obvious implication is that the debate on proximity and directional models of ideology, with which this chapter started, is shifted. The original question was: which model fits the data better? The question we have arrived at now is: which factors determine the slope and curvature of support curves?

The latter question has been addressed before. One factor of some importance for the structure of individual party evaluations refers to the political sophistication of voters. It is assumed that the proximity model requires a more complicated reasoning than the directional model, and that therefore less sophisticated voters are more likely to resort to directional thinking. The evidence for this assumption is however mixed (Macdonald et al. 1995; Maddens and Hajnal 20or).

Here we focus on a different aspect of elections that is likely to affect the way in which political parties are evaluated, namely the position of the political parties on the ideological left-right scale. The party position on that scale conveys information about how extreme, moderate, or centrist a party is in the eyes of the electorate. Party positions also lie at the basis of measures of party polarization.

According to directional theory, a moderately high degree of party polarization has favorable consequences for parties of the left or right, and unfavorable consequences for parties in the center. A low degree of party polarization would instead help parties in the center. When the major parties are all located near the center of the main policy dimension, the left and right parties among these do not enjoy the electoral advantage (according to directional theory) of being outspoken. According to proximity theory, parties of the center are always at an advantage provided that the distribution of voters also has its mass in the center. In both theories, differentiation of issue profiles of the parties enhances issue-based voting behavior (cf. Van Wijnen (200I) for the Dutch case).

An impact of polarization on party choice (and not just party evaluation) is also suggested by an earlier analysis of three elections in the Netherlands (1971, 1986, 1994) (Aarts et al. 1999). This analysis shows that when the major parties are relatively strongly polarized on the issues, parties in the center of the policy dimensions got fewer votes than when the major parties were less polarized. This finding supports directional theory.

Here we first use the mean perception of the respondents of the party position on the ideology scale. How is the party position on the left-right scale related to the slope of the party's support curve and its quadratic coefficient?

Figure 9.8 shows for 29I parties the regression of the value of the linear coefficient of the party support curve on the mean left-right position attributed to that party by the respondents. The relationship is strongly positive. Naturally, negative coefficients are almost exclusively found where the party position is on the left side of the neutral point and positive coefficients are associated with right-wing positions. But the linear coefficients (indicating the steepness of the support curve) are 
Figure 9.8 Party position and linear coefficient

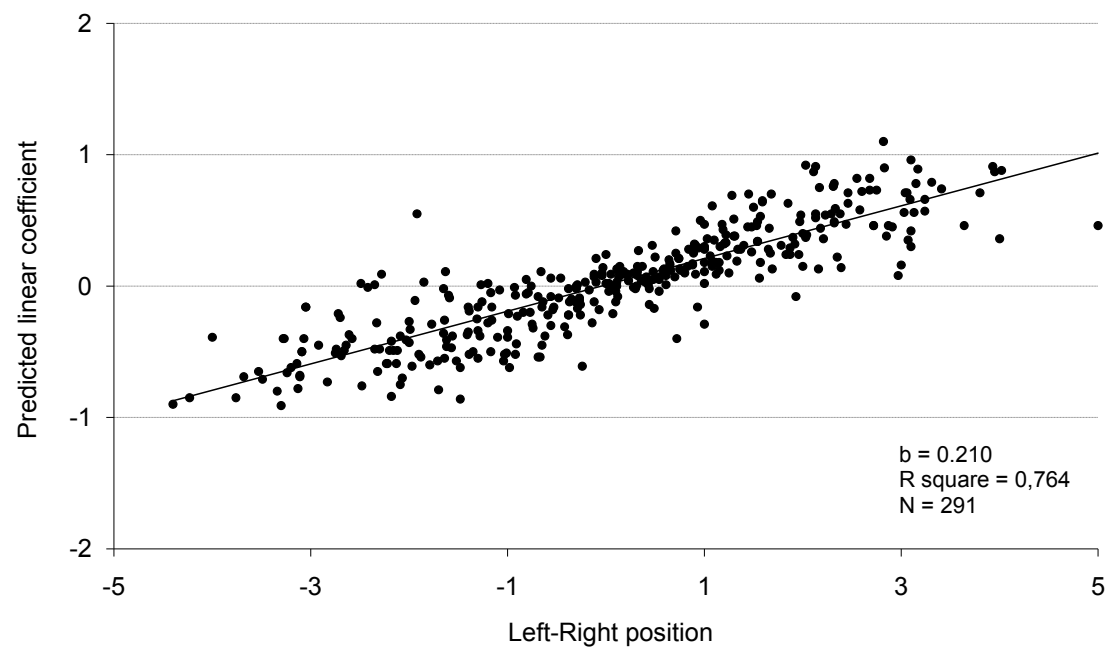

Source: CSES, Modules I and II

Figure 9.9 Absolute party position and quadratic coefficient

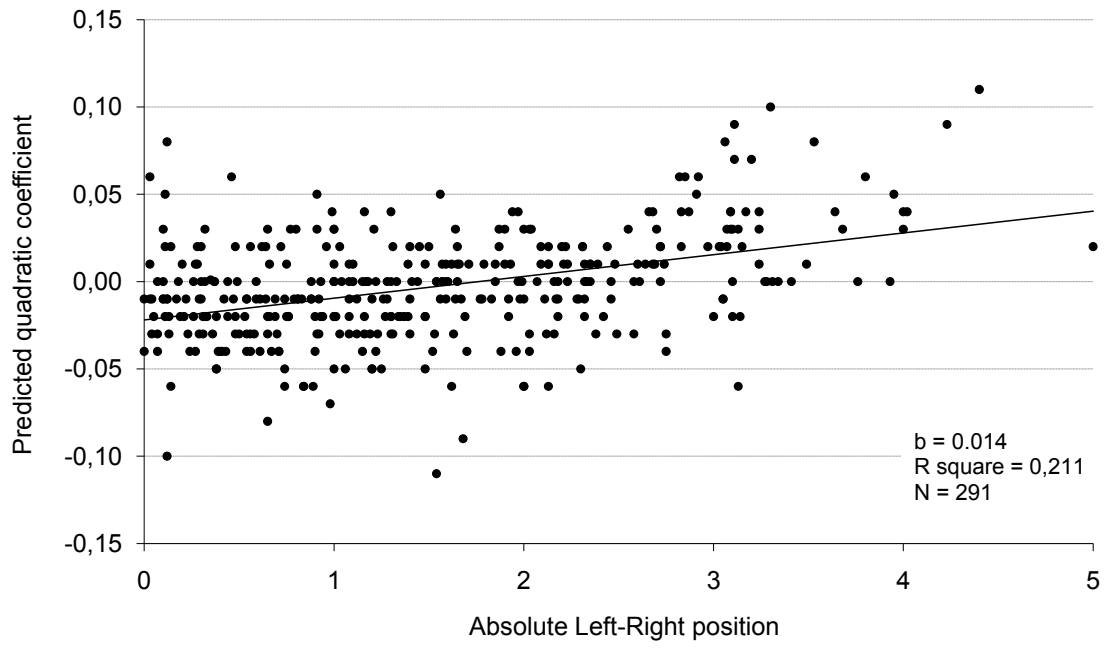

Source: CSES, Modules I and II 
also larger in the absolute sense when a party is further removed from the center. And conversely, center parties tend to have flatter curves. Figure 9.8 thus suggests a clear (linear) relationship between party position and the strength of feelings that the party evokes among the voters. In the terminology of the directional model: the clearer the commitment that parties show on ideology - either to the left or to the right -, the more important ideology becomes for the evaluation of the party.

In Figure 9.9, the relationship between party position and the quadratic coefficient of the support curve of the party is depicted. In this analysis, we use the absolute value of the mean left-right position of the party, since we expect that curvature only depends on the distance from the (neutral) center, and not on direction.

A support curve can reach a maximum value when the quadratic coefficient is negative (when it is positive, the curve has a minimum value instead). Inspecting Figure 9.9, it appears that negative quadratic coefficients tend to be found for parties that are relatively close to the (directionally) neutral point on the ideology scale: the closer the party position is to the center, the more curvature its support curve tends to show. Thus, Figure 9.9 suggests that the proximity logic tends to be more valid for center parties than for parties with a distinct left- or right-wing profile. But as was shown above, many support curves with curvature do not peak within the range of the ideology scale (as this depends on both the linear and the quadratic coefficients, it cannot be concluded from Figure 9.9 alone).

\subsection{Conclusion and discussion}

The question formulated at the beginning of this chapter was, how political parties deal with the tension between moderation and commitment when formulating their ideological position. This question was translated to the perceptions that voters have of political parties. From the voters' point of view, it refers to tenability of the key assumption of the proximity model, namely that party support among voters peaks at the ideological position of the party and drops off to both sides. Alternatively, the question could be rephrased to assess the tenability of the directional model of party support, which requires linear support functions that are steeper when parties are ideologically more extreme. We focused on a single operational measure of ideology, namely the left-right scale. In this contribution, we applied a parabolic regression model to 66 elections from all over the world.

The analyses have shown that the left-right is almost irrelevant for party support in II out of 66 cases. These cases have been dropped from subsequent analyses. Of the remaining $3 \mathrm{I} 7$ parties in 55 elections, only 7 percent shows support curves in accordance with the proximity model. At least 75 percent of the parties shows support curves which conform to the directional model.

Directional-type support curves are often found for parties with ideological position on the left or right, whereas the proximity-type curve is associated with center positions. 
It appears that no model of party support accommodates all political parties. That is in itself not a surprising result - party systems differ, parties differ, and in the literature the so-called mixed model of party support has been developed with this in mind. But in a discipline in which the proximity model still is the dominant, if not exclusive model taught in textbooks - and in political discourse characterized by the same dominance of proximity logic - it should lead to further thinking. The analysis relating party positions to the shape of the support curves suggested that party system polarization may be an important explanatory variable. But a measure of party system compactness does not exert a significant impact on the slope or curvature of support curves. Further analyses are needed to unravel the precise relationships between party system characteristics and the nature of the ideological evaluation of parties.

\section{Acknowledgement}

Previous versions of this text have been presented at the cses Conference and Planning Committee meeting in Sevilla, 28-3r March 2006, and at the Politics seminar of Nuffield College, Oxford, ro November 2006. Comments by the participants of these events were very helpful. The research benefited from a grant to Aarts by the Dutch Organization for Scientific Research Nwo (\# 400-04-706) and from Aarts' stay at the Netherlands Institute for Advanced Study in the Humanities and Social Sciences (NIAS).

\section{Notes}

I It is not necessary to ignore the possible penalty component of the directional model. Iversen, for example, (1994) provides a convincing operationalization of this term.

2 This does not imply that the voter would rather vote for the more intense party. There are many factors other than party evaluation that are weighted in the vote decision, including strategic considerations.

3 The concept and derivation of support curves (and their meaning for the evaluation of the proximity and directional models) has been the subject of some debate - see in particular the contributions by Westholm (I997, 200I) and those by Macdonald et al. (I998, 200I).

4 In Module I, the Thailand (200I) and Japan (1996) studies lack necessary data. In Portugal, the 2002 election study included both Module I and 2; we have used these data only once. The second German (2002) study (mail-back) has been omitted. Finally, in Module 2 the Japan (2004) study lacks necessary data.

5 The use of parabolic regression analysis in this contribution leans heavily on the description of the methodology by Listhaug et al. (1994).

6 Party evaluations have been centered around zero as well. 